\title{
Cholinergic septo-hippocampal innervation is required for trace eyeblink classical conditioning
}

\author{
Ángela Fontán-Lozano, ${ }^{1}$ Julieta Troncoso, ${ }^{1}$ Alejandro Múnera, ${ }^{2,3}$ \\ Ángel Manuel Carrión, ${ }^{1,3,4}$ and José María Delgado-García ${ }^{1,3}$ \\ ${ }^{1}$ División de Neurociencias, Universidad Pablo de Olavide de Sevilla, 41013-Sevilla, Spain; ${ }^{2}$ Departamento de Ciencias \\ Fisiológicas, Facultad de Medicina, Universidad Nacional de Colombia, Ciudad Universitaria, Bogotá, D.C., Colombia
}

\begin{abstract}
We studied the effects of a selective lesion in rats, with 192-IgG-saporin, of the cholinergic neurons located in the medial septum/diagonal band (MSDB) complex on the acquisition of classical and instrumental conditioning paradigms. The MSDB lesion induced a marked deficit in the acquisition, but not in the retrieval, of eyeblink classical conditioning using a trace paradigm. Such a deficit was task-selective, as lesioned rats were able to acquire a fixed-interval operant conditioning as controls, and was not due to nonspecific motor alterations, because spontaneous locomotion and blink reflexes were not disturbed by the MSDB lesion. The deficit in the acquisition of a trace eyeblink classical conditioning was reverted by the systemic administration of carbachol, a nonselective cholinergic muscarinic agonist, but not by lobeline, a nicotinic agonist. These results suggest a key role of muscarinic denervation on the acquisition of new motor abilities using trace classical conditioning procedures. It might also be suggested that muscarinic agents would be useful for the amelioration of some associative learning deficits observed at early stages in patients with Alzheimer's disease.
\end{abstract}

The cholinergic basal forebrain complex provides widespread and topologically organized cholinergic inputs to diverse brain regions, including the whole cortical mantle, the hippocampus, and the amygdala (Bigl et al. 1982). Numerous studies in experimental animals have indicated a critical role of basal forebrain cholinergic neurons in learning and memory processes (Hepler et al. 1985; Etherington et al. 1987; Everitt et al. 1987; Dunnett and Fibiger 1993). Early studies (using either aspiration or electrolytic procedures) showed that medial septal lesions induced cognitive deficits similar to those found after hippocampal lesions (for review, see Gray and McNaughton 1983). More recently, consistent learning deficits have been found in a large variety of tasks after immunotoxic or excitotoxic lesions of the nucleus basalis magnocellularis (Torres et al. 1994; Wenk 1997). These deficits have been ascribed to the resulting depletion of acetylcholine activity in cortical structures. At the same time, cholinergic dysfunction is thought to play a central role in the mnemonic disturbances observed in Alzheimer's disease (AD) patients. The rationale is that cholinergic transmission is greatly impaired in the early stages of $\mathrm{AD}$, when these memory deficits are first apparent (Davies and Maloney 1976; Bartus et al. 1982).

The role of the basal forebrain cholinergic system in learning has been widely debated. Early studies using nonspecific lesions of the nucleus basalis magnocellularis demonstrated striking deficits in a variety of learning paradigms, supporting a role for the basal forebrain cholinergic system in general learning and memory mechanisms (for review, see Olton and Wenk 1987). More recently, and in contrast, highly selective lesions of cholinergic neurons located in the basal forebrain, using the immunotoxin 192-IgG-saporin, have been found to produce only modest learning deficits in many of these same behavioral paradigms (for review, see Baxter and Chiba 1999).

\footnotetext{
${ }^{3}$ These authors contributed equally to this work. ${ }^{4}$ Corresponding author.

E-mail amancar@dex.upo.es; fax 34-954-349375.

Article published online ahead of print. Article and publication date are at http://www.learnmem.org/cgi/doi/10.1101/lm.28105.
}

The classical conditioning of blink responses can be used to evaluate the cognitive deficits induced by selective cholinergic lesions. This paradigm has significant parallels among humans, cats, rabbits, rats, and mice (Disterhoft et al. 1995; Gruart et al. 2000), and can be used to test brainstem/cerebellar systems (Thompson 1990) as well as higher limbic and cortical structures (Disterhoft et al. 1995). The finding that the acquisition of trace eyelid conditioned responses (CRs) is impaired by lesions in the hippocampus (Solomon et al. 1986; Weiss et al. 1999; Takatsuki et al. 2003) led to the prediction that in patients with AD-who have both hippocampal and cholinergic dysfunctions-eyeblink classical conditioning would be poorer than in normal adults. In fact, the acquisition of eyelid CRs, using a delay conditioning paradigm, is severely impaired in AD patients (Woodruff-Pak and Papka 1996). This learning impairment has also been found in transgenic mice overexpressing amyloid precursor protein using either delayed (Weiss et al. 2002) or trace (Dominguez-del-Toro et al. 2004) conditioning paradigms. Taken together, in this work we tried to establish the role played by the basal forebrain cholinergic system in the acquisition of trace eyelid CRs in comparison with deficits produced in other types of associative learning.

\section{Results}

The 76 rats used in this study were randomly assigned to one of the following four experimental paradigms: (1) to establish the consequences of the selective lesion of cholinergic neurons of the medial septum/diagonal band (MSDB) complex on the acquisition of eyelid CRs, (2) to determine whether the selective lesion of the MSDB complex affects retention of previously acquired eyelid CRs, (3) to determine whether selective MSDB-complex lesions impair the acquisition of a fixed-interval operant conditioning, and (4) to investigate the effect of systemic administration of cholinergic drugs on the learning deficit induced by these selective MSDB lesions.

The histological evaluation indicated that 192-IgG-saporin lesions eliminated nearly all cholinergic neurons within the 
MSDB complex (Fig. 1A,B). A quantitative analysis indicated that 192-IgG-saporin microinjections selectively depleted the population (up to 90\%) of cholinergic neurons located in the MSDB complex. Parvalbumin immunostaining (a known marker of prosencephalic GABAergic neurons) indicated that 192-IgGsaporin specifically depleted cholinergic neurons but did not cause any noticeable damage to the GABAergic cells also located in the MSDB complex (Fig. 1C,D).

As indicated above, an initial study was carried out to determine whether specific cholinergic lesions of the MSDB complex would impair the acquisition of eyelid CRs. Rats receiving a vehicle microinjection in the MSDB displayed a normal performance along the training period, reaching the conditioning criterion ( $>70 \%$ CRs in a given session) by the fourth conditioning session $\left(F_{(7,72)}=7.5, P=0.001\right.$; Fig. $2 \mathrm{~A}$, white circles). However, rats receiving bilateral MSDB microinjections of $100 \mathrm{ng}$ of 192IgG-saporin showed a significant deficit in the acquisition of eyelid CRs $\left(F_{(7,72)}=0.11, P=0.99\right.$; Fig. $2 \mathrm{~A}$, black circles $)$. The learning curve of the 192-IgG-saporin-injected group has a slope similar to that of the pseudoconditioned saline-injected group $\left(F_{(7,24)}=0.11, P=0.99\right.$; Fig. $2 \mathrm{~A}$, gray circles). However, the percentage of CRs in animals with a bilateral MSDB lesion was slightly higher, and significantly different from the percentage of CRs obtained from the pseudoconditioned saline-injected group (Fig. 2A).

To determine the effects of the selective lesion of cholinergic neurons located in the MSDB complex on the performance of previously acquired eyelid CRs, rats received a complete training (i.e., three habituation and seven conditioning sessions) before either saline or 192-IgG-saporin microinjection. Following a 21-d recovery period, the performance of each subject was tested using an additional session consisting of 60 paired conditioned stimulus-unconditioned stimulus (CS-US) trials. The retention index $(\mathrm{RI}=$ percentage of CRs during the test session/percentage of CRs during the last conditioning session) in saline- and 192-IgGsaporin-injected rats was close to unity $(0.9 \pm 0.12$ and $0.96 \pm 0.17$ for saline- and 192-IgG-saporin-injected rats, respectively; $\left.F_{(1,14)}=0.08, P=0.77\right)$. These results indicate that selective cholinergic MSDB lesions did not impair the performance of previously acquired eyelid CRs (Fig. 2B).

The noticeable difference in CR performance between 192IgG-saporin- and vehicle-injected animals was not due to a general motor impairment, as shown by the absence of significant differences in locomotor activity in the open field test. Thus,

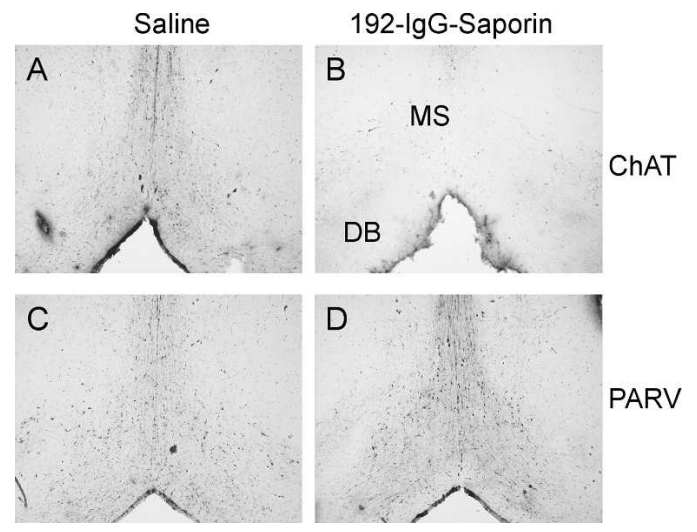

Figure 1. Bilateral 192-lgG-saporin microinjection depleted the MSDBcomplex cholinergic neuron population. Microphotographs of representative coronal sections through the MSDB complex of control and lesioned animals, immunohistochemically stained for cholineacetyltransferase (ChAT; $A, B)$ or parvalbumin (PARV; $C, D)$. MS, medial septum; DB, diagonal band; $n=10$ rats per group.

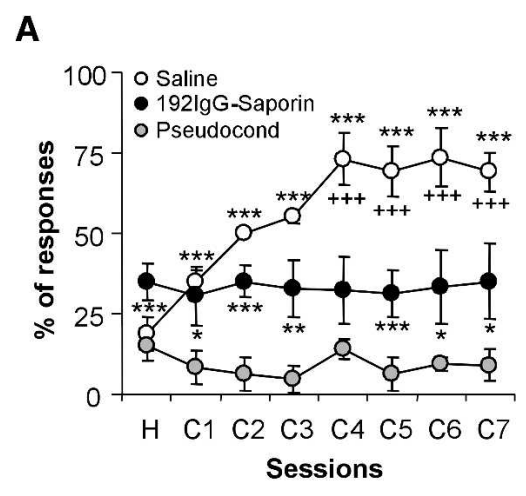

B

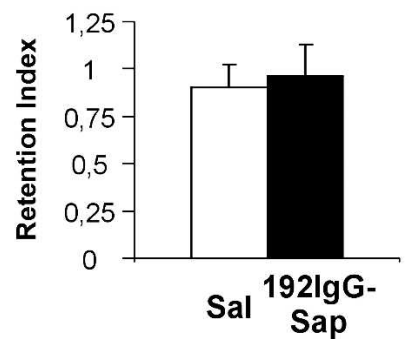

Figure 2. Acquisition of eyelid CRs in control and MSDB-lesioned rats. (A) A trace-conditioning paradigm was used to evaluate putative learning deficits in animals with a specific lesion of cholinergic neurons located in the MSDB complex. Learning curves of saline-injected rats (white circles, $n=10)$, 192-IgG-saporin-injected rats (black circles, $n=10$ ), and pseudoconditioned animals (gray circles, $n=4$ ). Because results obtained with 192lgG-saporin-injected rats during both pseudoconditioning and conditioning programs were similar, the pseudoconditioning curve has been omitted for the sake of clarity. ( $B$ ) Selective cholinergic MSDB lesions did not affect the retrieval of previously acquired eyelid CRs. Retention index: percentage of CRs during the test session/percentage of CRs during the last conditioning session. White bar, saline-injected rats; black bar, 192 IgG-saporin-injected rats ( $n=8$ per group). Pseudocond, pseudoconditioning saline-injected rats; *, significant differences between saline- or 192lgG-saporin-injected conditioned groups with respect to pseudoconditioned saline-injected groups; + , significant difference between salineand $192 \mathrm{lgG}$-saporin-injected groups. ${ }^{*},+, P \leq 0.05 ;{ }^{* *},++, P \leq 0.01 ;{ }^{* * *}$, ,$+++ P \leq 0.001$.

saline-injected animals presented a mean of $119.7 \pm 7.0$ broken beams/min, whereas 192-IgG-saporin-injected animals presented $114.3 \pm 6.0$ broken beams $/ \min \left(t_{(10)}=0.171, P=0.86\right.$; Fig. $\left.3 \mathrm{~A}\right)$.

The microinjection of 192-IgG-saporin did not affect reflex blinks, as determined by a quantitative analysis of the latency and amplitude of the electromyographic (EMG) activity of the orbicularis oculi muscle (see Domínguez-del-Toro at al. 2004 for details). The latencies of the R1 and R2 components (Kugelberg 1952) of reflexively evoked eyelid responses in intact rats during habituation were $7.7 \pm 0.3 \mathrm{msec}$ and $17 \pm 0.4 \mathrm{msec}$, respectively (Fig. 3B). The latencies did not change in these animals during the successive conditioning sessions $\left(F_{(3,31)}=0.82, P=0.49\right.$ for $\mathrm{R} 1 ; F_{(3,31)}=0.51, P=0.67$ for R2; Fig. 3B). In 192-IgG-saporininjected animals, R1 and R2 latencies did not change during the conditioning sessions compared to the values observed during habituation $\left(F_{(3,28)}=0.90, P=0.45\right.$ for R1; $F_{(3,28)}=2.27, P=0.11$ for R2; Fig. 3B). Furthermore, a direct comparison between salineand 192-IgG-saporin-injected rats with respect to R1 and R2 latencies did not show any significant difference $\left(F_{(7,56)}=0.87\right.$, $P=0.53$ for $\mathrm{R} 1 ; F_{(7,56)}=1.09, P=0.38$ for R2). As amplitude analysis gives an idea of a possible sensitization of the evoked blink reflex, R1 and R2 amplitudes were measured at different 
A
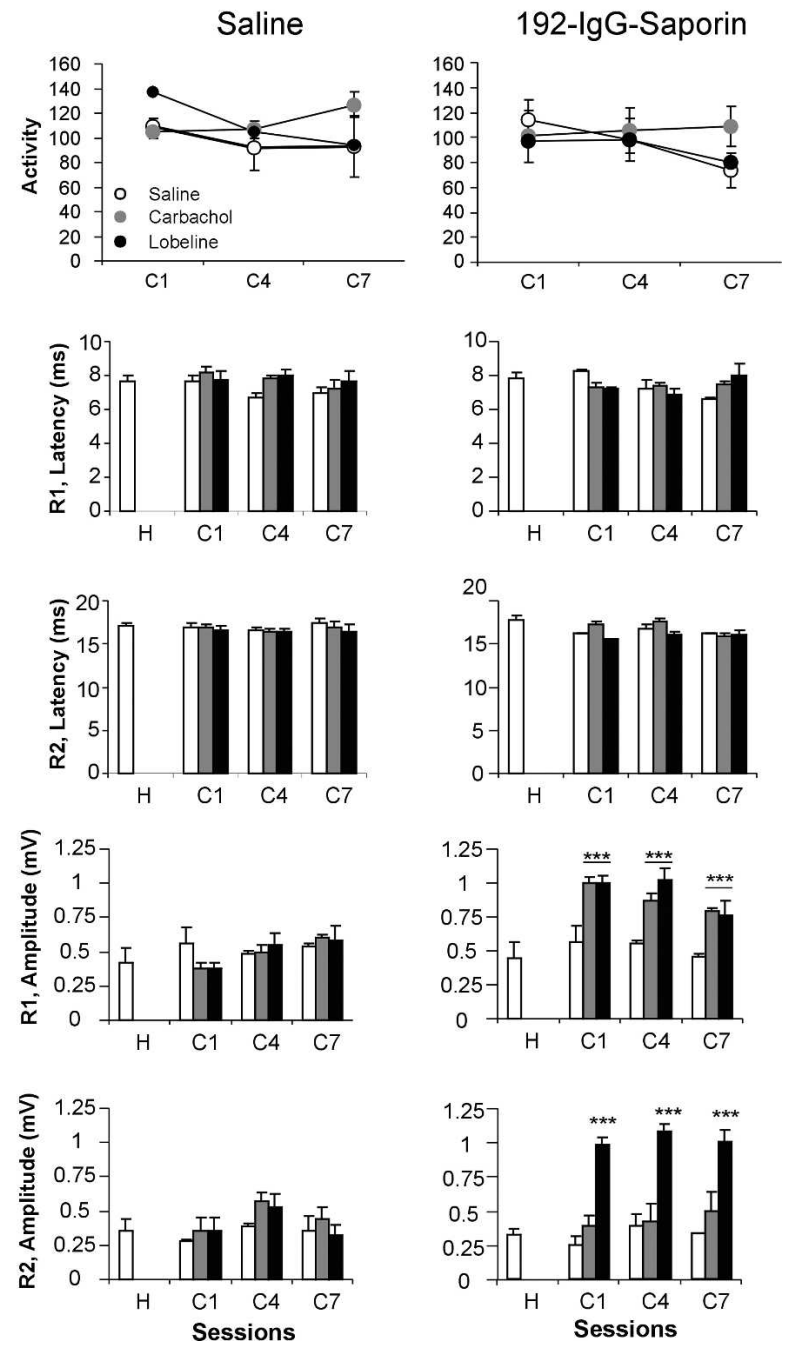

Figure 3. Locomotor activity and blink reflex basic properties in salineand 192-lgG-saporin-injected rats treated with different cholinergic agonists. $(A)$ Locomotor activity, as indicated by the number of broken beams in a 10-min period, of saline- (left panel) and 192-lgG-saporin(right panel) injected rats measured $1 \mathrm{~h}$ after cholinergic drug administration in selected conditioning sessions. Open circles, saline; gray circles, carbachol; black circles, lobeline. $(B, C)$ Bar diagrams representing the mean \pm SEM of the latency ( $B$, in $\mathrm{msec}$ ) and peak amplitude $(C$, in $\mathrm{mV})$ of the R1 (upper row) and R2 (lower row) components of blink reflex in saline- (left column) and 192-lgG-saporin- (right column) injected animals $1 \mathrm{~h}$ after cholinergic drug administration during habituation and selected conditioning sessions ( $n=6$ per group). Systemic treatments: saline, white bars; $0.1 \mathrm{mg} / \mathrm{kg}$ carbachol, gray bars; $1 \mathrm{mg} / \mathrm{kg}$ lobeline, black bars. ${ }^{*}, P \leq 0.05 ;{ }^{* *}, P \leq 0.01 ;{ }^{* *}, P \leq 0.001$. Abbreviations on the $x$-axis refer to $(\mathrm{H})$ habituation or $(\mathrm{C})$ conditioning sessions.

stages of training (habituation and first, fourth, and seventh conditioning sessions) in saline- and 192-IgG-saporin-injected rats (Fig. 3C). The amplitudes did not change in the saline- or 192IgG-saporin-injected rats during the successive conditioning sessions $\left(F_{(3,20)}=0.57, P=0.63\right.$ for R1 and $F_{(3,20)}=1.27, P=0.31$ for R2 in saline-injected rats; $F_{(3,20)}=0.01, P=0.99$ for R1 and $F_{(3,20)}=0.59, P=0.62$ for R2 in 192-IgG-saporin-injected rats). These results contrast with previous reports in cats (Gruart et al. 1995) and rabbits (Gruart et al. 2000)-namely, rats (as mice; see Inda et al. 2005) did not present any evidence of reflex response sensitization (i.e., alpha responses) in a similar (shock-SHOCK) trace conditioning paradigm. Moreover, direct comparison of R1 and R2 amplitudes between the 192-IgG-saporin- and salineinjected groups did not show any significant difference $\left(F_{(7,40)}=0.59, P=0.75\right.$ for R1; $F_{(7,40)}=0.18, P=0.98$ for R2). These results, taken together, indicate that 192-IgG-saporin administration did not impair the normal kinematics of the eyelid motor system.

Furthermore, we wanted to know whether the MSDBcomplex lesion affected the acquisition of an operant conditioning task. At the end of the first phase of training (lever-pressing/ food-pellet association), no significant differences were found between saline- and 192-IgG-saporin-injected groups $\left(F_{(1,18)}=2.35\right.$, $P=0.143$; Fig. 4A). When the subjects were shifted to a 30 -sec fixed-interval schedule (Fig. 4B), the two experimental groups showed similar evolution in the total number of pellets obtained (for saline-injected rats: $F_{(9,90)}=4.89, P<0.001$; for 192-IgGsaporin-injected rats: $\left.F_{(9,90)}=5.98, P<0.001\right)$ and in the number of conditioned responses along the training period (for salineinjected rats: $F_{(9,90)}=7.53, P<0.001$; for 192-IgG-saporininjected rats: $\left.F_{(9,90)}=12.85, P<0.001\right)$. On the tenth day of training, no significant difference was observed between the two experimental groups in the number of total and conditioned pellets obtained (total pellets per session: $F_{(1,18)}=0.16, P=0.69$; conditioned pellets per session: $\left.F_{(1,18)}=1.35, P=0.26\right)$.

Finally, it was determined whether the administration of two cholinergic agonists, either carbachol $(0.1 \mathrm{mg} / \mathrm{kg}$, s.c. $)$ or lobeline (1 $\mathrm{mg} / \mathrm{kg}$, s.c.), during the acquisition of eyelid CRs could revert the learning deficit observed in animals with the lesion of the cholinergic neurons located in the MSDB complex. Carbachol, a nonspecific muscarinic receptor agonist, was able to revert the cognitive deficits in the acquisition of eyelid CRs ob-

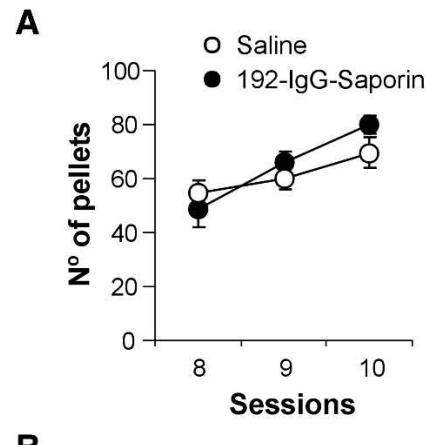

B

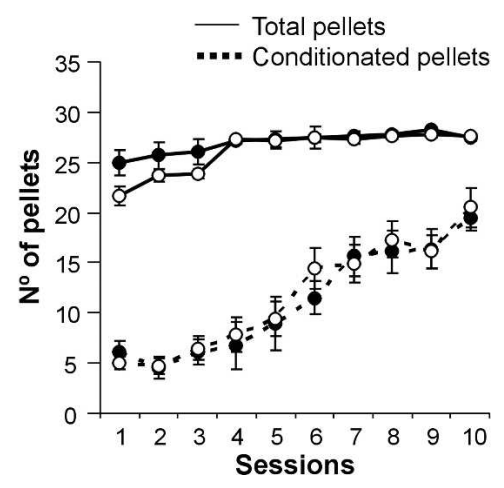

Figure 4. Acquisition of operant conditioning in control and MSDBlesioned rats. $(A)$ Effect of selective cholinergic MSDB lesion on the last three sessions of the training to associate reinforcements with lever pressures. (B) Learning curves of saline- and 192-lgG-saporin-injected rats ( $n=10$ per group) during the 10 sessions of a 30 -sec fixed-interval program. Continuous line, total number of pellets per session; discontinuous line, number of pellets obtained by conditioned lever pressures per session. Saline-injected rats (०), 192-IgG-saporin-injected rats (•). 
served in lesioned animals $\left(F_{(7,42)}=5.80, P<0.001\right.$; Fig. 5B), making this group indistinguishable from the saline-injected group. However, carbachol did not significantly modify the performance of saline-injected animals (Fig. 5A). Lobeline, a nicotinic receptor agonist, slightly improved the learning rate of lesioned animals $\left(F_{(7,42)}=2.21, P=0.07\right.$; Fig. $\left.5 \mathrm{~B}\right)$. On the other hand, lobeline did not significantly modify the performance of salineinjected animals (Fig. 5A). Neither carbachol nor lobeline had any secondary effect on locomotor activity (Fig. 3A) or on the latency of the R1 and R2 components of reflexively evoked blinks (Fig. 3B) in saline- and 192-IgG-saporin-injected animals. Both carbachol and lobeline significantly increased R1 amplitude only in 192-IgG-saporin-injected animals $\left(t_{(10)}=4.91, P<0.001\right.$ for the first conditioning session; $t_{(10)}=7.76, P<0.001$ for the fourth conditioning session; $t_{(10)}=5.14, P<0.001$ for the seventh conditioning session in carbachol-injected rats; $t_{(10)}=6.81$, $P<0.001$ for the first conditioning session; $t_{(10)}=3.34, P<0.001$ for the fourth conditioning session; $t_{(10)}=4.11, P<0.001$ for the seventh conditioning session in lobeline-injected rats; Fig. 3C). Additionally, lobeline significantly increased R2 amplitude only in 192-IgG-saporin-injected animals $\left(t_{(10)}=9.34, P<0.001\right.$ for the first conditioning session; $t_{(10)}=6.9, P<0.001$ for the fourth conditioning session; $t_{(10)}=4.5, P<0.001$ for the seventh conditioning session; Fig. 3C).

\section{Discussion}

The trace classical conditioning of eyelid responses is a useful associative task for examining the effects of selective cholinergic MSDB lesions, because this type of motor learning has been shown to be hippocampus-dependent in mice (Takehara et al. 2002, 2003; Tseng et al. 2004), rabbits (Solomon et al. 1986; Moyer Jr. et al. 1990; Kim et al. 1995), cats (Múnera et al. 2001), and humans (McGlinchey-Berroth et al. 1997). Additionally, the acquisition of eyelid CRs is significantly impaired in aged animals (Disterhoft et al. 1995; Thompson et al. 1996; Knuttinen et al. 2001) and in AD patients (Solomon et al. 1991; Woodruff-Pak and Papka 1996). To evaluate the role of the cholinergic septal system in trace eyeblink classical conditioning, we performed bilateral 192-IgG-saporin microinjections in the MSDB complex. This immunotoxin induces targeted death of MSDB cholinergic neurons and the shrinkage of cholinergic terminals in the hippocampus and in some neocortical regions in about 3 wks (Pizzo et al. 1999).

The present results demonstrate that the selective lesion of
A

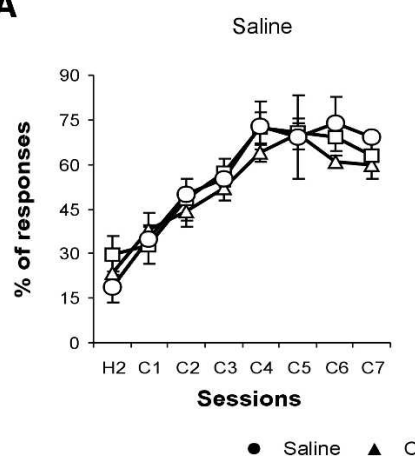

B

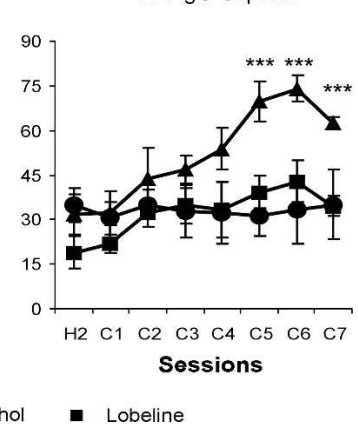

Figure 5. Learning curves of classically conditioned eyelid responses in saline- and 192-lgG-saporin-injected rats treated with different cholinergic agonists. $(A)$ Learning curves of saline-injected rats treated with saline $(O), 0.1 \mathrm{mg} / \mathrm{kg}$ carbachol $(\triangle)$, or $1 \mathrm{mg} / \mathrm{kg}$ lobeline ( $\square)$. (B) Learning curves of $192-\mathrm{lgG}$-saporin-injected rats treated with saline $(\bullet), 0.1 \mathrm{mg} / \mathrm{kg}$ carbachol $(\boldsymbol{\Delta})$, or $1 \mathrm{mg} / \mathrm{kg}$ lobeline $(\boldsymbol{\nabla}) .{ }^{*}, P \leq 0.05 ;{ }^{* *}, P \leq 0.01 ;{ }^{* * *}$, $P \leq 0.001$ ( $n=6$ rats per group). Abbreviations on the $x$-axis refer to $(H)$ habituation or $(C)$ conditioning sessions. cholinergic MSDB neurons disrupts the acquisition of trace eyelid CRs, but not of fixed-interval operant conditioning. Furthermore, we demonstrated that this acquisition deficit is not due to a nonspecific motor impairment, as this lesion did not modify the animals' locomotor behavior or the normal kinematics of reflex blink responses. In addition, we found that the selective lesion of cholinergic MSDB neurons does not affect the performance of previously acquired eyelid CRs. This fact could be due to the neurodegenerative process induced by 192-IgG-saporin, which is not as immediate (i.e., it took between 15 and 20 d) as hippocampal ablations or electroshock administration. Probably, during this time the hippocampus transfers the acquired new information to other neocortical structures, as suggested by others (Kim et al. 1995; Takehara et al. 2003). On the other hand, an effect of the lesion on eyelid alpha responses should not be misestimated. These data suggest that the integrity of the cholinergic septo-hippocampal system is not necessary for the acquisition of a fixed-interval operant conditioning or for the performance of a consistently acquired $\mathrm{CR}$, using a classical conditioning paradigm. Conversely, the activity of this cholinergic septohippocampal system seems to play a crucial role in the acquisition of trace eyelid CRs.

The specific deficit induced by the selective lesion of cholinergic MSDB neurons in the acquisition of trace eyelid CRs was completely reverted by systemic administration of carbachol, a nonspecific muscarinic receptor agonist. The effects of carbachol on different limbic system structures are very well known and may be explained by the induction of calcium-activated nonspecific cationic currents (Klink and Alonso 1997; Yajeya et al. 1999). In contrast, this deficit was not reverted by the systemic administration of lobeline, a nicotinic receptor agonist (RoshanMilani et al. 2003). Thus, it can be inferred that a lack of muscarinic receptor activation is responsible for the learning deficit observed here following the almost complete lesion of the population of MSDB neurons in rats. However, both agonists produced an increase in the amplitude of the blink reflex response in saporin-injected rats, a finding probably due to the activation of the neural components of the eyelid motor, and pre-motor, system (Múnera et al. 2000).

The development of 192-IgG-saporin, a selective cholinergic neurotoxin, enabled the demonstration that the exclusive destruction of cholinergic cells of the basal forebrain does not impair many learning paradigms (Berger-Sweeney et al. 1994; Torres et al. 1994; Baxter et al. 1996; Baxter and Chiba 1999). It was recently reported that selective cholinergic basal forebrain lesions impair the acquisition of a motor skill learning paradigm (Conner et al. 2003). Here, we show that this kind of lesion is an appropriate model for the study of $\mathrm{AD}$, because it causes cholinergic hypofunction in the paleocortex and a severe, specific impairment in the acquisition of trace eyelid CRs using classical conditioning paradigms. Moreover, this cognitive deficit can be useful in the search for cognition-enhancing agents. At the same time, 192-IgG-saporin-injected animals can be used as a model of attentive deficits, another frequent symptom in $\mathrm{AD}$ patients (Lawrence and Sahakian 1995).

The trace classical conditioning paradigm used here, presenting conditioned and unconditioned stimuli of the same sensory modality, has been used (with minor modifications) in cats (Gruart et al. 1995; Múnera et al. 2001), rabbits (Gruart et al. 2000), and mice (Domínguez-del-Toro et al. 2004; Inda et al. 2005). The main advantage of this procedure is that it allows free displacements of the experimental animal in the recording chamber, without expected modifications in the intensity and/or properties of the stimuli used as CS and US, as can happen when using a tone or a light as a CS.

The classical conditioning of eyelid responses using a trace 
paradigm induces characteristic changes in the firing properties of hippocampal pyramidal cells associated with a theta-to-beta shift in pyramidal layer field activity during the CS-US interval (Múnera et al. 2001). Changes induced in hippocampal activity by eyeblink conditioning could be determined by septal cholinergic inputs. In fact, acetylcholine release is enhanced during paired CS-US presentations using classical conditioning procedures (Meyer et al. 1996). Muscarinic blockade (Solomon et al. 1983; Kaneko and Thompson 1997; Múnera et al. 2000) and medial septal lesions (Berry and Thompson 1979) impair the acquisition of eyelid CRs. Conversely, cholinergic agonists improve the acquisition of CRs in old animals (Weiss et al. 2000; Woodruff-Pak and Santos 2000). Our results confirm a specific role of MSDB cholinergic neurons in the acquisition of eyelid CRs using a trace paradigm, for the following reasons: (1) the depletion of cholinergic MSDB neurons causes a severe impairment in the acquisition of eyelid CRs but not of fixed-interval operant conditioning; (2) this deficit is reverted by carbachol administration; and (3) when the MSDB lesion was performed in fully conditioned rats, retrieval of conditioned lid responses was not affected, when evaluated 3 wks after the lesion. This last finding reinforces the idea that the septo-hippocampal system has a relevant role in the acquisition of CRs using a trace paradigm, whereas information retrieval is dependent on other structures, such as the medial prefrontal cortex (Takehara et al. 2002, 2003; Dudai 2004).

It has been reported that both muscarinic and nicotinic cholinergic receptors are associated with neuronal plasticity and with learning and memory processes (Van der Zee et al. 1997). The present data suggest that muscarinic agonists can be a good therapeutic approach to alleviating cognitive deficits associated with AD (Weiss et al. 2000). Although cholinesterase inhibitors and M1 agonists produced similar results during eyeblink conditioning in aging rabbits (Weiss et al. 2000; Simon et al. 2004; Weible et al. 2004), the latter would be more favorable because of its specificity. The use of muscarinic agonists is also indirectly profitable, because the activation of cell surface receptors that are positively coupled to phospholipase C, including M1 and M3, results in the increased release of soluble amyloid precursor protein (Nitsch et al. 1992; Hung et al. 1993; Robinson and Harrell 1997) and a reduction in $\beta$-amyloid peptide observed in vitro (Buxbaum et al. 1992; Nitsch et al. 1992; Hung et al. 1993). These findings suggest that, in addition to alleviating cognitive symptoms of the cholinergic depletion, muscarinic receptor activation may interfere with $\beta$-amyloid formation.

\section{Materials and Methods}

\section{Subjects}

Seventy-six male Wistar rats supplied by an official supplier (Animal Services, University of Granada, Spain) were used as subjects. At the time of surgery, they weighed 250-300 g. Animals were housed in standard polycarbonate cages in a colony room under a 12-h light/12-h dark cycle. Water and food were available ad libitum. All experiments were carried out in accordance with the guidelines of the European Union Council (86/609/EU) and following Spanish regulations (BOE 67/8509-12, 1988) for the use of laboratory animals in chronic experiments.

\section{Surgical procedures}

All surgical procedures were carried out under ketamine/xylazine anesthesia $(80: 8 \mathrm{mg} / \mathrm{kg})$ and using aseptic surgical techniques. A 0.5 - $\mu \mathrm{L}$ volume of either 192-IgG-saporin (Chemicon International), diluted to a concentration of $0.2 \mathrm{mg} / \mathrm{mL}$ in artificial cerebrospinal fluid, or vehicle (artificial cerebrospinal fluid alone) was injected close to each side of the MSDB complex (stereotaxic coordinates: AP: + $0.7 \mathrm{~mm}$; L: $\pm 0.4 \mathrm{~mm}$; D: $-6.6 \mathrm{~mm}$ from bregma). Microinjections were made using a $0.5-\mu \mathrm{L}$ Hamilton syringe at a rate of $0.1 \mu \mathrm{L} / \mathrm{min}$. After each injection, the needle remained in place for $5 \mathrm{~min}$ to permit diffusion of the injected fluid into the parenchyma. All rats were allowed $21 \mathrm{~d}$ to recover from the surgery before the behavioral testing was started.

For experiments in which the rats had to receive a lesion just after the last conditioning session, two intracerebral guidecannulae were implanted near both MSDB complexes. The cannulae were attached firmly to the skull with dental acrylic resin and anchored to it using two small stainless steel screws. In these subjects, the selected microinjection was carried out just after the end of the eyelid classical conditioning, inserting the $0.5-\mu \mathrm{L}$ Hamilton syringe needle through each cannula and following the above described procedure.

In the same surgical session, four Teflon-coated stainless steel wires (No. 7910; A-M Systems) were implanted in the subcutaneous tissue of the right upper eyelid. The wires were soldered to a four-pin connector that was secured to the skull with dental acrylic resin and stainless steel screws.

\section{Drug administration}

Carbachol and lobeline were dissolved in sterile saline. Rats received subcutaneous injections of $0.1 \mathrm{mg} / \mathrm{kg}$ of carbachol (SigmaAldrich), $0.5 \mathrm{mg} / \mathrm{kg}$ of lobeline (Sigma), or an equivalent volume of sterile saline. Doses were selected following preliminary studies of locomotor activity in the open field (data not shown). The chosen doses were the larger ones that did not evoke any alteration in locomotor activity in saline-injected animals. Injections were carried $30 \mathrm{~min}$ before the beginning of each session.

\section{Locomotor activity measurement}

Locomotion was measured in a $26 \times 39 \mathrm{~cm}$ activity box (Cibertec) as the number of broken light beams during 10-min periods. Measurements of locomotor activity were carried out $1 \mathrm{~h}$ after drug administration on days 1,4 , and 7 . The effects of 192IgG-saporin on locomotor activity were evaluated with a $t$-test. A two-way ANOVA was applied to determine any possible difference in the effects of drug administration on locomotor behavior between successive days. In addition, $t$-tests with Tukey correction were used for post hoc comparisons.

\section{Eyeblink classical conditioning}

For the classical conditioning of eyelid responses, each rat was placed in a Plexiglas chamber $(20 \times 20 \times 20 \mathrm{~cm})$ located in a sound- and light-attenuated chamber. A low-weight, fourchannel wire was connected to the socket implanted on the animal's head. The CS and US consisted respectively of 50- and 500-usec cathodic electrical pulses, delivered through the pair of electrodes implanted in the right upper periorbital region, close to the supraorbitary branch of the trigeminal nerve. CS and US intensities (in $\mathrm{mA}$ ) were experimentally determined for each subject before the beginning of the training and were not changed along the conditioning program. CS intensity was defined as the minimum intensity able to elicit a small eyelid movement associated with the presence of a reflex response in the EMG activity of the orbicularis oculi muscle (OOM). US intensity was that able to consistently elicit a complete and immediate eyelid closure. A 250-msec stimulus-free interval was interposed between the end of the CS and the onset of the US. Eyelid responses were monitored using the EMG activity of the OOM, recorded through the second pair of eyelid electrodes. Further details of this experimental preparation are presented elsewhere (Domínguez-delToro et al. 2004; Inda et al. 2005).

Training was started 3 wks after surgery. The complete classical conditioning training consisted of 10 daily 60-trial sessions: three habituation (CS-alone trials) and seven conditioning (paired CS-US trials) sessions. The intertrial interval was randomized between 25 and $35 \mathrm{sec}$. The pseudoconditioning training consisted of seven daily sessions, during which 60 CS and 60 US were presented at random. In all behavioral experiments, a total of 6-8 animals per group were used.

The EMG activity of the OOM was filtered using a band- 
width of $1 \mathrm{~Hz}$ to $10 \mathrm{kHz}$, digitized online at a sampling rate of 10 $\mathrm{kHz}$, and stored on a computer for off-line analysis. EMG analysis was performed by someone blind to the condition of animal and treatment. A trial was assumed to contain a CR if a definite EMG activity (i.e., one lasting $>10 \mathrm{msec}$ ) appeared 50-250 msec after the CS presentation; thus, we avoided including putative alpha responses in the quantification of true CRs. Those recordings presenting EMG activity in the $250 \mathrm{msec}$ preceding CS presentation (change in baseline) or with an evident startle response (response beginning $4 \mathrm{msec}$ after CS and expanded until $100 \mathrm{msec}$ ) or artifactual recordings were rejected from the quantitative analysis. The percentage of trials containing a CR in a given session was calculated on the basis of the number of valid trials. The latency and amplitude of the two components of reflex blink responses (denominated R1 and R2 by Kugelberg 1952), evoked by stimuli equal to that used as CS, were measured and compared before and during different phases of the training.

Differences in the amplitude and latency of the R1 and R2 components of the EMG response during reflex blinks were evaluated with two-way ANOVA, with drug administration (saline, 192-IgG-saporin) as between-subject factor, and conditioning session (habituation, and first, fourth, and seventh conditioning sessions) as within-subject factor; $t$-tests with Tukey correction were applied for post hoc comparisons.

Performance during acquisition and retrieval is expressed as the mean percentage of eyelid conditioned responses per session. Changes in behavior as a function of drug administration were evaluated by applying a one-way ANOVA, with conditioning session (eight sessions) as within-subject factor, and drug administration (saline, and 192-IgG-saporin) as between-subject factor; $t$-tests with Tukey correction were applied for the post hoc comparisons.

\section{Operant conditioning}

Training was carried out using a Skinner's box (Cibertec). Starting 2 wks before training, all rats were handled daily. The weight of the subjects $10 \mathrm{~d}$ before training was used as baseline for a food restriction regime. Subjects were weighed daily in order to allow enough food to maintain their body weight at $80 \%$ of the baseline.

All rats received an initial 10-d training to associate leverpressing with a food pellet reinforcer. Once they had acquired such association, rats were submitted to a 30-sec fixed-interval reinforcement schedule (a single reinforcer was delivered if the rat pressed the bar at least once during a 30-sec interval). In this schedule, a reinforced lever pressure was considered conditioned if and only if it occurred during the second half of the interval (between seconds 16-30).

\section{Tissue preparation and immunohistochemistry}

In order to analyze cholineacetyltransferase and parvalbumin immunoreactivity, rats from each experimental group were sacrificed by decapitation at the end of the experiments. Their brains were removed and placed on an ice-cold plate. The tissue was fixed by immersion in $4 \%$ paraformaldehyde in phosphatebuffered saline (PBS) for $24 \mathrm{~h}$ at $4^{\circ} \mathrm{C}$, and cryoprotected in $30 \%$ sucrose PBS for $2 \mathrm{~d}$ at $4^{\circ} \mathrm{C}$. Brains were then embedded in $30 \%$ sucrose and kept at $4^{\circ} \mathrm{C}$ until cryotome sectioning. Coronal sections $(50 \mu \mathrm{m})$ were obtained from each brain and processed for free-floating immunohistochemistry (De los Santos-Arteaga et al. 2003). The specific cholineacetyltransferase (Chemicon) and parvalbumin (Sigma) antisera were used at 1:500 and 1:2000 dilutions, respectively.

\section{Acknowledgments}

We thank Mrs. M.C. Sutil, Miss M.D. Marín, and Miss M. Cadena for technical assistance with animal housing, and Mr. R. Churchill for editorial help. J.T. was a predoctoral student supported by the Spanish Carolina Foundation. This work was sup- ported by AECI, Junta de Andalucía (CVI-122), and DGICYT (BFI2002-00936) grants.

\section{References}

Bartus, R.T., Dean III R.L., Beer, B., and Lippa, A.S. 1982. The cholinergic hypothesis of geriatric memory dysfunction. Science 217: 408-414.

Baxter, M.G. and Chiba, A.A. 1999. Cognitive functions of the basal forebrain. Curr. Opin. Neurobiol. 9: 178-183.

Baxter, M.G., Bucci, D.J., Sobel, T.J., Williams, M.J., Gorman, L.K., and Gallagher, M. 1996. Intact spatial learning following lesions of basal forebrain cholinergic neurons. Neuroreport 7: 1417-1420.

Berger-Sweeney, J., Heckers, S., Mesulam, M.M., Wiley, R.G., Lappi, D.A., and Sharma, M. 1994. Differential effects on spatial navigation of immunotoxin-induced cholinergic lesions of the medial septal area and nucleus basalis magnocellularis. J. Neurosci. 14: 4507-4519.

Berry, S.D. and Thompson, R.F. 1979. Medial septal lesions retard classical conditioning of the nictitating membrane response in rabbits. Science 205: 209-211.

Bigl, V., Woolf, N.J., and Butcher, L.L. 1982. Cholinergic projection from the basal forebrain to frontal, parietal, temporal, occipital, and cingulate cortices: A combined fluorescent tracer and acetylcholinesterase analysis. Brain Res. Bull. 8: 727-749.

Buxbaum, J.D., Oishi, M., Chen, H.I., Pinkas-Kramarski, R., Jaffe, E.A., Gandy, S.E., and Greengard, P. 1992. Cholinergic agonists and interleukin 1 regulate processing and secretion of the Alzheimer B/A4 amyloid protein precursor. Proc. Natl. Acad. Sci. 89: $10075-10078$.

Conner, J.M., Culberson, A., Packowski, C., Chiba, A.A., and Tuszynski, M.H. 2003. Lesions of the basal forebrain cholinergic system impair task acquisition and abolish cortical plasticity associated with motor skill learning. Neuron 38: 819-829.

Davies, P. and Maloney, A.J. 1976. Selective loss of central cholinergic neurons in Alzheimer's disease. Lancet 2: 1403.

De los Santos-Arteaga, M., Sierra-Domínguez, S.A., Fontanella, G.H., Delgado-García, J.M., and Carrión, A.M. 2003. Analgesia induced by dietary restriction is mediated by the к-opioid system. J. Neurosci. 23: $1120-1126$.

Disterhoft, J.F., Thompson, L.T., Weiss, C., Moyer, J.R., Van der Zee, E., Carrillo, M., Kronforst-Collins, M., and Power, J. 1995. The calcium hypothesis for Alzheimer's disease: Insights from animal and human studies. Neurosci. Res. Commun. 17: 121-131.

Domínguez-del-Toro, E., Rodríguez-Moreno, A., Porras-García, E. Sánchez-Campusano, R., Blanchard, V., Lavilla, M., Bohme, G.A. Benavides, J., and Delgado-García, J.M. 2004. An in vitro and in vivo study of early deficits in associative learning in transgenic mice that over-express a mutant form of human APP associated with Alzheimer's disease. Eur. J. Neurosci. 20: 1945-1952.

Dudai, Y. 2004. The neurobiology of consolidations, or, how stable is the engram? Annu. Rev. Psychol. 55: 51-86.

Dunnett, S.B. and Fibiger, H.C. 1993. Role of forebrain cholinergic system in learning and memory: Relevance to cognitive deficits of ageing and Alzheimer's dementia. Progr. Brain Res. 98: 413-420.

Etherington, R.E., Mittleman, G., and Robbins, T.W. 1987. Comparative effects of nucleus basalis and fimbria-fornix lesions on delayed matching and alteration tests memory. Neurosci. Res. Commun. 22: 441-469.

Everitt, B.J., Robbins, T.W., Evenden, J.L., Marston, H.M., Jones, G.H., and Sirkia, T.E. 1987. The effects of excitotoxic lesions of the substantia innominata, ventral and dorsal globus pallidus on the acquisition and retention of a conditional visual discrimination: Implication for cholinergic hypothesis of learning and memory. Neuroscience 22: 441-469.

Gray, J.A. and McNaughton, N. 1983. Comparison between the behavioural effects of septal and hippocampal lesions: A review. Neurosci. Biobehav. Rev. 7: 119-188.

Gruart, A., Blázquez, P., and Delgado-García, J.M. 1995. Kinematics of spontaneous, reflex, and conditioned eyelid movements in the alert cat. J. Neurophysiol. 74: 226-248.

Gruart, A., Schreurs, B.G., Domínguez del Toro, E., and Delgado-García, J.M. 2000. Kinetic and frequency-domain properties of reflex and conditioned eyelid responses in the rabbit. J. Neurophysiol. 83: $836-852$.

Hepler, D.J., Wenk, G.L., Cribbs, B.L., Olton, D.S., and Coyle, J.T. 1985. Lesions in nucleus basalis magnocellularis and medial septal area of rats produce qualitatively similar memory impairments. J. Neurosci. 5: $866-873$.

Hung, A.Y., Haass, C., Nitsch, R.M., Qiu, W.Q., Citron, M., Wurtman, R.J., Growdon, J.H., and Selkoe, D.J. 1993. Activation of protein kinase C inhibits cellular production of the amyloid $\beta$ protein. $J$. Biol. Chem. 268: 22959-22962. 
Inda, M.C., Delgado-García, J.M., and Carrión, A. 2005. Acquisition, consolidation, reconsolidation, and extinction of eyelid conditioning response require de novo protein synthesis. J. Neurosci. 25: $2070-2080$.

Kaneko, T. and Thompson, R.F. 1997. Disruption of trace conditioning of the nictitating membrane response in rabbits by central cholinergic blockade. Psychopharmacology 131: 161-166.

Kim, J.J., Clark, R.E., and Thompson, R.F. 1995. Hippocampectomy impairs the memory of recently, but not remotely, acquired trace eyeblink conditioned responses. Behav. Neurosci. 109: 195-203.

Klink, R. and Alonso, A. 1997. Ionic mechanism of muscarinic depolarization in entorhinal cortex layer II neurons. J. Neurophysiol. 77: 1829-1843.

Knuttinen, M.G., Gamelli, A.E., Weiss, C., Power, J.M., and Disterhoft, J.F. 2001. Age-related effects on eyeblink conditioning in the F344 $\times$ BN F1 hybrid rat. Neurobiol. Aging 22: 1-8.

Kugelberg, E. 1952. Facial reflexes. Brain 75: 385-396.

Lawrence, A.D. and Sahakian, B.J. 1995. Alzheimer disease, attention, and the cholinergic system. Alzheimer. Dis. Assoc. Disor. 9: 43-49.

McGlinchey-Berroth, R., Carrillo, M.C., Gabrieli, J.D.E., Brawn, C.M., and Disterhoft, J.F. 1997. Impaired trace eyeblink conditioning in bilateral medial temporal lobe amnesia. Behav. Neurosci. 111: $873-882$

Meyer, J.J., Allen, D.D., and Yokel, R.A. 1996. Hippocampal acetylcholine increases during eyeblink conditioning in the rabbit. Physiol. Behav. 60: 1199-1203.

Moyer Jr., J.R., Deyo, R.A., and Disterhoft, J.F. 1990. Hippocampectomy disrupts trace eye-blink conditioning in rabbits. Behav. Neurosci. 104: $243-252$.

Múnera, A., Gruart, A., Muñoz, M.D., and Delgado-García, J.M. 2000. Scopolamine impairs information processing in the hippocampus and performance of a learned eyeblink response in alert cat. Neurosci. Lett. 292: 33-36.

Múnera, A., Gruart, A., Muñoz, M.D., Fernández-Más, R., and Delgado-García, J.M. 2001. Discharge properties of identified CA1 and CA3 hippocampus neurons during unconditioned and conditioned eyelid responses in cats. J. Neurophysiol. 86: 2571-2582.

Nitsch, R.M., Slack, B.E., Wurtman, R.J., and Growdon, J.H. 1992. Release of Alzheimer amyloid precursor derivatives stimulated by activation of muscarinic acetylcholine receptors. Science 258: 304-307.

Olton, D.S. and Wenk, G.L. 1987. Dementia: Animal models of the cognitive impairments produced by degeneration of the basal forebrain cholinergic system. In Psychopharmacology: The third generation of progress (ed. H.Y. Meltzer), pp. 941-953. Raven Press, New York.

Pizzo, D.P., Waite, J.J., Thal, L.J., and Winkler, J. 1999. Intraparenchymal infusions of 192 IgG-saporin: Development of a method for selective and discrete lesioning of cholinergic basal forebrain nuclei. I. Neurosci. Method 91: 9-19.

Robinson, M.R. and Harrell, L.E. 1997. Cholinergic activity and amyloid precursor protein metabolism. Brain Res. Rev. 25: 50-69.

Roshan-Milani, S., Ferrigan, L., Khoshnood, M.J., Davies, C.H., and Cobb, S.R. 2003. Regulation of epileptiform activity in hippocampus by nicotinic acetylcholine receptor activation. Epilepsy Res. 56: $51-65$.

Simon, B.B., Knuckley, B., and Powell, D.A. 2004. Galantamine facilitates acquisition of a trace-conditioned eyeblink response in healthy, young rabbits. Learn. Mem. 11: 116-122.

Solomon, P.R., Solomon, S.D, Schaaf, E.V., and Perry, H.E. 1983. Altered activity in the hippocampus is more detrimental to classical conditioning than removing the structure. Science 220: 329-331.

Solomon, P.R., Van der Schaaf, E.R., Thompson, R.F., and Weisz, D.J. 1986. Hippocampus and trace conditioning of the rabbit's classically conditioned nictitating membrane response. Behav. Neurosci. 100: $729-744$

Solomon, P.R., Levine, E., Bein, T., and Pendlebury, W.W. 1991. Disruption of classical conditioning in patients with Alzheimer's disease. Neurobiol. Aging 12: 283-287.

Takatsuki, K., Kawahara, S., Kotani, S., Fukunaga, S., Mori, H., Mishina, M., and Kirino, Y. 2003. The hippocampus plays an important role in eyeblink conditioning with a short trace interval in glutamate receptor subunit $\delta 2$ mutant mice. J. Neurosci. 23: 17-22.

Takehara, K., Kawahara, S., Takatsuki, K., and Kirino, Y. 2002. Time-limited role of the hippocampus in the memory for trace eyeblink conditioning in mice. Brain Res. 951: 183-190.

Takehara, K., Kawahara, S., and Kirino, Y. 2003. Time-dependent reorganization of the brain components underlying memory retention in trace eyeblink conditioning. J. Neurosci. 23: 9897-9905.

Thompson, R.F. 1990. Neural mechanisms of classical conditioning in mammals. Philos. Trans. R. Soc. Lond. B Biol. Sci. 329: 161-170.

Thompson, L.T., Moyer Jr., J.R., and Disterhoft, J.F. 1996. Trace eyeblink conditioning in rabbits demonstrates heterogeneity of learning ability both between and within age groups. Neurobiol. Aging 17: 619-629.

Torres, E.M., Perry, T.A., Blockland, A., Wilkinson, L.S., Wiley, R.G., Lappi, D.A., and Dunnett, S.B. 1994. Behavioural, histochemical and biochemical consequences of selective immunolesions in discrete regions of the basal forebrain cholinergic system. Neuroscience 63: $95-122$.

Tseng W., Guan, R., Disterhoft, J.F., and Weiss, C. 2004. Trace eyeblink conditioning is hippocampally dependent in mice. Hippocampus 14: $58-65$.

Van der Zee, E.A., Kronforst-Collins, M.A., Maizels, E.T., Hunzicker-Dunn, M., and Disterhoft, J.F. 1997. $\gamma$ Isoform-selective changes in PKC immunoreactivity after trace eyeblink conditioning in the rabbit hippocampus. Hippocampus 7: 271-285.

Weible, A.P., Oh, M.M., Lee, G., and Disterhoft, J.F. 2004. Galantamine facilitates acquisition of hippocampus-dependent trace eyeblink conditioning in aged rabbits. Learn. Mem. 11: 108-115.

Weiss, C., Bouwmeester, H., Power, J.M., and Disterhoft, J.F. 1999. Hippocampal lesions prevent trace eyeblink conditioning in the freely moving rat. Behav. Brain Res. 99: 123-132.

Weiss, C., Preston, A.R., Oh, M.M., Schwarz, R.D., Welty, D., and Disterhoft, J.F. 2000. The M1 muscarinic agonist CI-1017 facilitates trace eyeblink conditioning in aging rabbits and increases the excitability of CA1 pyramidal neurons. J. Neurosci. 20: 783-790.

Weiss, C., Venkatasubramanian, P.N., Aguado, A.S., Power, J.M., Tom, B.C., Li, L., Chen, K.S., Disterhoft, J.F., and Wyrwicz, A.M. 2002. Impaired eyeblink conditioning and decreased hippocampal volume in PDAPP V717F mice. Neurobiol. Dis. 11: 425-433.

Wenk, G.L. 1997. The nucleus basalis magnocellularis cholinergic system: One hundred years of progress. Neurobiol. Learn. Mem. 67: 85-95.

Woodruff-Pak, D.S. and Papka, M. 1996. Alzheimer's disease and eyeblink conditioning: $750 \mathrm{~ms}$ trace vs. $400 \mathrm{~ms}$ delay paradigms. Neurobiol. Aging 17: 397-404.

Woodruff-Pak, D.S. and Santos, I.S. 2000. Nicotinic modulation in an animal model of a form of associative learning impaired in Alzheimer's disease. Behav. Brain Res. 113: 11-19.

Yajeya, J., de la Fuente, J.A., Bajo, V.M., Riolobos, A.S., Heredia, M., and Criado, J.M. 1999. Muscarinic activation of a non-selective cationic conductance in pyramidal neurons in rat basolateral amygdala. Neuroscience 88: 159-167.

Received April 11, 2005; accepted in revised form August 26, 2005. 


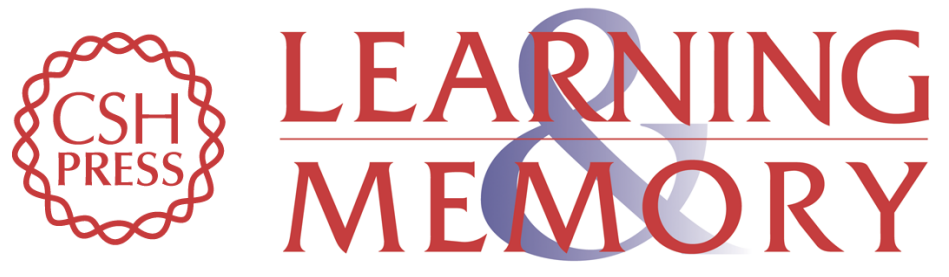

\section{Cholinergic septo-hippocampal innervation is required for trace eyeblink classical conditioning}

Ángela Fontán-Lozano, Julieta Troncoso, Alejandro Múnera, et al.

Learn. Mem. 2005, 12:

Access the most recent version at doi:10.1101//m.28105

References This article cites 55 articles, 14 of which can be accessed free at:

http://learnmem.cshlp.org/content/12/6/557.full.html\#ref-list-1

License

Email Alerting Receive free email alerts when new articles cite this article - sign up in the box at the Service top right corner of the article or click here. 